\title{
Modelling of Indicator Escherichia coli Contamination in Sentinel Oysters and Estuarine Water
}

\author{
Saharuetai Jeamsripong $1, * \mathbb{D}$ and Edward R. Atwill ${ }^{2}$ \\ 1 Research Unit in Microbial Food Safety and Antimicrobial Resistance, Department of Veterinary Public \\ Health, Faculty of Veterinary Science, Chulalongkorn University, Pathumwan, Bangkok 10330, Thailand \\ 2 Western Institute for Food Safety and Security, School of Veterinary Medicine, University of California, \\ Davis, CA 95618, USA; ratwill@ucdavis.edu \\ * Correspondence: saharuetai.j@gmail.com; Tel.: +66-94-654-3412
}

Received: 24 April 2019; Accepted: 21 May 2019; Published: 4 June 2019

\begin{abstract}
This study was performed to improve the ability to predict the concentrations of Escherichia coli in oyster meat and estuarine waters by using environmental parameters, and microbiological and heavy metal contamination from shellfish growing area in southern Thailand. Oyster meat $(n=144)$ and estuarine waters $(n=96)$ were tested for microbiological and heavy metal contamination from March 2016 to February 2017. Prevalence and mean concentrations of E. coli were $93.1 \%$ and $4.6 \times 10^{3}$ most probable number (MPN)/g in oyster meat, and 78.1\% and $2.2 \times 10^{2} \mathrm{MPN} / 100 \mathrm{~mL}$ in estuarine water. Average 7-day precipitation, ambient air temperature, and the presence of Salmonella were associated with the concentrations of E. coli in oyster meat $(p<0.05)$. Raw data (MPN/g of oyster meat and MPN/100 mL of estuarine water) and log-transformed data (logMPN/g of oyster meat and $\log \mathrm{MPN} / 100 \mathrm{~mL}$ of estuarine water) of $E$. coli concentrations were examined within two contrasting regression models. However, the more valid predictions were conducted using non-log transformed values. These findings indicate that non-log transformed data can be used for building more accurate statistical models in microbiological food safety, and that significant environmental parameters can be used as a part of a rapid warning system to predict levels of $E$. coli before harvesting oysters.
\end{abstract}

Keywords: Crassostrea; Escherichia coli; estuarine water; fecal contamination; heavy metal contamination; log-transformation; Salmonella; Shigella

\section{Introduction}

The consumption of raw seafood products, especially bivalves, poses potential risks for human health, since bivalves are effective filler feeders that can concentrate both nutrients and hazardous substances from the environment [1]. Bivalves can accumulate high bacterial loads and chemical contamination. Numerous seafood-borne outbreaks of Salmonella, Shigella, Vibrio parahaemolyticus, Vibrio vulnificus, Streptococcus aureus and Clostridium botulinum derived from oysters have been continuously reported globally [2-5]. The most common route of oyster-borne outbreaks has been traced to the consumption of raw or minimally-cooked oyster meat [6]. Heavy metal contamination in oyster meat has also been investigated in different locations. For example, in northern Vietnam, high levels of $\mathrm{Zn}, \mathrm{Cu}, \mathrm{As}, \mathrm{Cd}, \mathrm{Pb}$ and $\mathrm{Cr}$ were reported in rocky oysters, and in the north-central coast of Sinaloa in Mexico, the contamination of $\mathrm{Zn}, \mathrm{Cu}, \mathrm{Cd}, \mathrm{Pb}$, and $\mathrm{Hg}$ was observed in oyster meat intended for human consumption $[7,8]$.

Laboratory microbiological analyses of pathogenic bacteria are generally expensive, difficult to perform and time-consuming; as a consequence, the determination of indicator bacteria i.e., fecal coliform and Escherichia coli, can be used as proxy to identify fecal contamination in seafood products 
and in harvested area [9]. In seafood safety monitoring programs, bivalves have been frequently used as a good environmental and biological indicator to identify contamination [10].

In field-based studies, average ambient air temperature, relative humidity, wind speed, seasons, geographical location, climate change, and aquatic animal captive approaches have been found to have had a strong influence on biological and chemical contamination of shellfish products [11]. Climate change is currently a global concern and it may contribute to a myriad of environmental factors such as heavy precipitation and temperature increase, influencing the persistence of bacterial impact on the dispersal of foodborne pathogens to the environment [12,13]. In oyster cultivation, main sources of fecal contamination from the environment to bivalve cultivation areas have been reported to come from domestic animals, wildlife, water runoff, birds, recreational sports, and sewage [14]. Nevertheless, it is challenging to identify the exact source of contamination to seafood products, which is often impractical, infeasible, and very difficult to perform. Therefore, monitoring and surveillance of environmental parameters can be adopted to predict bacterial accumulation in oyster meat and estuarine water.

Authorities from different countries such as the United States, the European Union (EU) and New Zealand have established national standards or guidelines regarding microbial contamination of shellfish, and criteria for determining the safety of shellfish intended for human consumption [15-17]. However, in many countries, including Thailand, no stringent guideline or standard has been strictly implemented with regard to the allowed level of E. coli contamination in fresh oysters for human consumption. Monitoring of environmental parameters, together with testing the concentrations of indicator bacteria of bivalves and estuarine waters in aquaculture growing areas, should be performed public health reasons. This information can also help farmers to identify the proper time to harvest oysters in order to decrease possible pathogenic bacterial contamination.

This study was conducted to improve the ability to predict the concentrations of $E$. coli in oyster meat and estuarine waters by using environmental parameters, the concentrations of total coliforms, fecal coliforms, and V. parahaemolyticus, the presence of Salmonella and Shigella, and levels of heavy metal contamination, including lead, manganese, and cadmium, in the Phang Nga area of southern Thailand. Many previous microbiological quality studies have primarily used log-transformed data to illustrate their results. Therefore, no log and log-transformed data of E. coli concentrations were used to generate and compare mixed-effect regression models of cultivated oysters and estuarine waters under tropical environmental conditions. The main objective of this study was to compare mixed regression models of oysters and estuarine waters, using non-log and log-transformed data to generate proper microbiological data.

\section{Materials and Methods}

\subsection{Sample Collection}

In this study, the data collection was conducted in aggregation with another experiment connected to a previous study [18]. Wild-caught natural oyster larvae, or spats, have been mainly used for oyster aquaculture in southern Thailand. These oyster larvae settle and attach to either man-made bamboo poles or motorcycle tires. When the oysters reach the age of 2-3 months, they are relocated to a grow-out structure cultivated area. The oyster shells are attached to one another on a nylon rope with cement. Oysters are raised under this hanging method until they reach the age of 10-12 months, which is provides market sized fresh oyster products.

A total of 240 samples derived from mature cultivated oysters (Crassostrea lugubris and Crassostrea belcheri) $(n=144)$ and estuarine waters $(n=96)$ were collected from March 2016 to February 2017 along the Phang Nga bay, Thap pud district, Krabi province in southern Thailand. Pooled oyster samples $(n=12)$ containing 10-12 market size oysters, and 500-mL samples of estuarine water $(n=8)$ were collected from four oyster cultivation sites each month for one year. All samples were kept in a cool box with ice pack during transportation. Following collection, oyster meat and 
estuarine water samples were processed immediately after arrival at the laboratory of the Department of Veterinary Public Health in Faculty of Veterinary Science in Chulalongkorn University.

\subsection{Environmental Data Collection}

Environmental parameters were measured, including average daily and weekly ambient air temperature $\left({ }^{\circ} \mathrm{C}\right)$, relative humidity $(\%)$, maximum wind gust $(\mathrm{m} / \mathrm{s})$, wind speed $(\mathrm{m} / \mathrm{s})$, and precipitation $(\mathrm{mm})$. Average daily environmental data was received on the day that samples were collected, and the data was recorded using a mobile anemometer wind meter (Kestrel 3000, Boothwyn, PA, USA). For average 7-day environmental parameters, all variable values were measured every three $h /$ days, and then summarized. These 7-day environmental parameters were retrieved from the Thai meteorological department (https://www.tmd.go.th). Other factors, such as the presence of precipitation (present or absent), season (rain, summer, or winter), sampling month (month 1 to 12), and tidal condition (ebbing or flooding), were also recorded in this study.

\subsection{Enumeration of Total Coliforms, Fecal Coliforms, E. coli and V. parahaemolyticus}

The levels of total coliforms, fecal coliforms, E. coli and V. parahaemolyticus were quantified as most probable number (MPN) using a three-tube method, while the presence or absence of Salmonella and Shigella were tested in the oyster and estuarine water samples. Enumeration of total coliforms, fecal coliforms, and E. coli followed the United States Food and Drug Administration (U.S. FDA) Biological Analytical Manual (BAM) [19]. Briefly, $200 \mathrm{~g}$ of pooled oyster meat was blended at high speed for at least $30 \mathrm{~s}$. Fifty grams of blended oyster meat were weighed and added to $450 \mathrm{~mL}$ of sterile phosphate buffered saline (PBS) (Difco, Sparks, MD, USA). For estuarine water, the sample was mixed with PBS at a 1:10 dilution. The remaining blended oyster meat and estuarine water were kept for further bacterial and heavy metal analyses. The mixture solution of each oyster and estuarine water sample was individually diluted in lactose broth (Difco) and incubated at $37^{\circ} \mathrm{C}$ overnight. One loopful of individual lactose broth tube was transferred to brilliant green lactose bile (BGLB) (Difco) and incubated at $35^{\circ} \mathrm{C}$ for $24 \mathrm{~h}$. Then, positive tubes were recorded. To confirm fecal coliforms, a loopful of lactose broth tube was transferred to EC broth (Difco). After overnight incubation at $44.5^{\circ} \mathrm{C}$, the gas production was recorded as positive. For confirmation of E. coli, a loopful of EC broth was streaked onto Levine-eosin methylene blue (L-EMB) (Difco) agar plates. The suspected E. coli colonies were streaked on plate count agar (PCA) (Difco), and then confirmed using biochemical testing.

Measurement of concentrations of $V$. parahaemolyticus in pooled oyster meat and estuarine water samples also followed the U.S. FDA's BAM method [20]. Briefly, mixture solution of the prepared samples from the previous step was serially diluted in alkaline peptone water (APW) (Difco) in three consecutive tubes to determine the populations of $V$. parahaemolyticus in oyster and estuarine water samples. The APW tubes were incubated at $37^{\circ} \mathrm{C}$ overnight, and then a loopful from APW positive (turbid) tubes was streaked to thiosulfate-citrate-bile salts-sucrose (TCBS) (Difco) agar plate and confirmed by CHROMagar ${ }^{\mathrm{TM}}$ Vibrio (HiMedia Laboratories Ltd., Mumbai, India) agar plate. Positive colonies were biochemically confirmed.

In determining bacterial loads in all samples from oyster and estuarine water, the concentrations of total coliforms, fecal coliforms. E. coli, and V. parahaemolyticus were reported in MPN/g or logMPN/g of oyster meat and MPN/100 mL or logMPN/100 mL of estuarine water.

\subsection{Determination of Salmonella spp. and Shigella spp.}

The detection of Salmonella and Shigella followed protocols as described by the U.S. FDA's BAM method, with slight modification [21,22]. Twenty-five g of oyster meat was enriched with $225 \mathrm{~mL}$ of lactose broth (difco), and estuarine water was mixed with double strength lactose broth. The mixture solution of the samples was set at room temperature $\left(25^{\circ} \mathrm{C}\right)$ for $60 \mathrm{~min}$. Then, the suspension was incubated at $35^{\circ} \mathrm{C}$ overnight. Each mixture solution $(0.1 \mathrm{~mL})$ was transferred into $10 \mathrm{~mL}$ of Rappaport-vassiliadis (RV) (Difco). A loopful of the suspension was streaked onto xylose 
lysine deoxycholate (XLD) (Difco), MacConkey (Difco) and Hektoen enteric (HE) (Difco) agar plates. Biochemical testing was then used to confirm presumptive colonies of Salmonella spp. For all positive Salmonella isolates, serotyping on a slide agglutination assay followed the Kaufman-White scheme method, based on commercial antiserum (S\&A Reagents Lab, Bangkok, Thailand) [23].

For Shigella spp. detection, briefly, a total of $25 \mathrm{~g}$ of blended oyster meat and $25 \mathrm{~mL}$ of estuarine water were separately enriched with Shigella and Salmonella broth (Difco). The mixture suspension was incubated at $35^{\circ} \mathrm{C}$ overnight. A loopful of suspension was streaked onto MacConkey (Difco) agar plate. All positive colonies were confirmed using biochemical testing.

\subsection{Determination of Heavy Metals}

Concentrations of lead $(\mathrm{Pb})$, cadmium $(\mathrm{Cd})$ and manganese $(\mathrm{Mn})$ in pooled oyster meat and estuarine water samples were analyzed following the guidelines of the Association of Analytical Communities [24]. Briefly, $5 \mathrm{~g}$ samples of blended pooled oyster meat were weighed out, and then dried over an oven. The sample was added to $\mathrm{HNO}_{3}$ concentrate (Merck, Washington, DC, USA). The mixture solution was dried over a hot plate to receive one $\mathrm{ml}$ of residue. For each estuarine water sample, a total of $200 \mathrm{~mL}$ of water was thoroughly mixed and filtered, passing through $11 \mu \mathrm{m}$ filter paper (Whatman, Maidstone, UK). The filtered solution was added to $30 \mathrm{~mL}$ of $\mathrm{HNO}_{3}$ and set overnight at room temperature. The mixture solution was then dried, and adjusted to the final solution by adding distilled water to receive $25 \mathrm{~mL}$. The final solution of all samples was then filtered, passing through $0.45 \mu \mathrm{m}$ filter paper (Whatman) and kept in the refrigerator for further analysis. The concentrations of $\mathrm{Pb}, \mathrm{Cd}$, and $\mathrm{Mn}$ were quantified using the Atomic Absorption Spectrophotometry (AAS: Varian model AA280FS, Agilent, USA) in the Science and Technology Research Equipment Centre (STRE) at Chulalongkorn University.

\subsection{Statistical Analyses}

The concentrations of $E$. coli in both pooled oyster meat and estuarine water samples were used in two different regression models. The dependent variable of the levels of $E$. coli was separately calculated on raw, or non-transformed, data (MPN/g of oyster meat and MPN/100 mL of estuarine water) and $\log$-transformed data (logMPN/g of oyster meat and $\log \mathrm{MPN} / 100 \mathrm{~mL}$ of estuarine water). Mixed-effect regression models were used to describe the association between the concentrations of $E$. coli in oyster meat or estuarine water samples, and average daily and 7-day environmental parameters, bacterial contamination of total coliforms and fecal coliforms, Salmonella, Shigella, and V. parahaemolyticus, and the levels of $\mathrm{Pb}, \mathrm{Mn}$ and $\mathrm{Cd}$. The $p$-values and C.I.'s of regression analyses for potential correlated data within the same location were adjusted by using a robust variance estimator. Univariate analysis and a backward elimination analysis were performed to build the multivariable mixed-effects regressions of pooled oysters and estuarine waters. The criteria used to select biological, chemical, and environmental factors affecting the concentrations of E. coli were based on potential biological meaning and AICs of individual models in order to select appropriate mixed-effect regression models. To perform all statistical analyses, Stata version 14 software (StatacCorp LP, College Station, TX, USA) was used.

\section{Results}

Average daily and 7-day environmental parameters on maximum wind gust (m/s), current wind speed $(\mathrm{m} / \mathrm{s})$, precipitation $(\mathrm{mm})$, ambient air temperature $\left({ }^{\circ} \mathrm{C}\right)$ and relative humidity $(\%)$ were summarized (Table 1). No log or log-transformed data were calculated and then used to compare within the same sample type. No log-transformed or raw data of the concentrations of $E$. coli of MPM/g of oysters (Model A) and log-transformed data of logMPM/g of oysters (Model B), and MPN/100 mL of estuarine water (Model C) and logMPN/100 mL of estuarine water (Model D) were then compared. 
Table 1. Summary of 1-day and 7-day data for descriptive statistics on environmental parameters collected by Thai metrological department station prior to collection of oysters and estuarine waters over 12 months from March 2016 to February 2017.

\begin{tabular}{|c|c|c|c|c|c|c|c|c|}
\hline \multirow{2}{*}{ Parameter } & \multirow{2}{*}{ Med } & \multirow{2}{*}{ SD } & \multirow{2}{*}{ Min } & \multirow{2}{*}{$\operatorname{Max}$} & \multicolumn{3}{|c|}{ Pooled Oyster ( $p$-Value ${ }^{\mathbf{1}}$ ) } & \multirow{2}{*}{$\begin{array}{c}\begin{array}{c}\text { Estuarine Water } \\
\left(p \text {-Value }{ }^{1}\right)\end{array} \\
\text { Model D }^{3}\end{array}$} \\
\hline & & & & & Model A ${ }^{2}$ & Model B ${ }^{3}$ & Model C $^{2}$ & \\
\hline \multicolumn{9}{|l|}{ 1-day environmental data } \\
\hline Maximum wind gust $(\mathrm{m} / \mathrm{s})$ & 6.2 & 2.4 & 5.2 & 12.9 & 0.001 & $<0.0001$ & 0.968 & 0.313 \\
\hline Current wind speed $(\mathrm{m} / \mathrm{s})$ & 0.8 & 0.4 & 0.0 & 1.5 & 0.002 & 0.066 & 0.713 & 0.383 \\
\hline Precipitation $(\mathrm{mm})$ & 2.4 & 28.8 & 0.0 & 87.8 & $<0.0001$ & 0.001 & $<0.0001$ & $<0.0001$ \\
\hline Temperature $\left({ }^{\circ} \mathrm{C}\right)$ & 28.0 & 1.5 & 25.2 & 29.7 & 0.020 & $<0.0001$ & 0.008 & $<0.0001$ \\
\hline Relative humidity (\%) & 83.0 & 7.8 & 74.0 & 97.0 & $<0.0001$ & $<0.0001$ & $<0.0001$ & $<0.0001$ \\
\hline \multicolumn{9}{|l|}{ 7-day environmental data } \\
\hline Maximum wind gust $(\mathrm{m} / \mathrm{s})$ & 6.6 & 1.9 & 5.6 & 11.4 & $<0.0001$ & $<0.0001$ & $<0.0001$ & $<0.0001$ \\
\hline Current wind speed $(\mathrm{m} / \mathrm{s})$ & 1.0 & 0.4 & 0.6 & 1.8 & $<0.0001$ & $<0.0001$ & $<0.0001$ & $<0.0001$ \\
\hline Precipitation $(\mathrm{mm})$ & 19.1 & 24.4 & 0.0 & 79.8 & $<0.0001$ & $<0.0001$ & $<0.0001$ & $<0.0001$ \\
\hline Temperature $\left({ }^{\circ} \mathrm{C}\right)$ & 27.3 & 1.0 & 26.1 & 29.6 & $<0.0001$ & $<0.0001$ & $<0.0001$ & $<0.0001$ \\
\hline Relative humidity (\%) & 86.1 & 4.9 & 78.3 & 92.7 & $<0.0001$ & $<0.0001$ & $<0.0001$ & $<0.0001$ \\
\hline
\end{tabular}

${ }_{1} p$-values were adjusted for potential intra-group correlation within sampling locations; ${ }^{2}$ No log of $E$. coli (MPN/g of oyster meat or MPN/100 mL of estuarine water); ${ }^{3}$ LogMPN of E. coli (LogMPN/g of oyster or LogMPN/100 mL of estuarine water; Med: Median; SD: Standard Deviation; Min: Minimum; Max: Maximum.

Under the univariate analysis, most environmental variables were found to be of significance $(p<0.05)$ in predicting the concentrations of $E$. coli in oyster meat and estuarine water, except the daily maximum wind gust in the Models $C$ and D, and the daily current wind speed in the Models B, C, and D (Table 1).

In this study, the concentrations of E. coli ranged from 4.6 to $2.2 \times 10^{4} \mathrm{MPN} / \mathrm{g}$ of pooled oyster meat, and 8.0 to $4.6 \times 10^{3} \mathrm{MPN} / 100 \mathrm{~mL}$ of estuarine waters. The prevalence of $E$. coli was observed in $93.06 \%$ of oyster meat and $78.13 \%$ of estuary water. In this study, the lower limit of detection was approximately $5 \mathrm{MPN}$ of E. coli/g of oyster meat and $8 \mathrm{MPN}$ of E. coli/100 mL of estuarine water. The detection of Shigella and Salmonella were $7.64 \%$ and $30.56 \%$ of pooled oyster meat. Prevalence of Shigella was as high as $27.08 \%$ in $100 \mathrm{~mL}$ of estuarine waters, while no positive Salmonella was observed in pooled oyster meat samples. The positive Salmonella isolates from oyster meat samples were serotyped, and the results of this Salmonella serotyping showed that dominant serotypes were Paratyphi B 22.7\% $(n=10 / 44)$ followed by Seremban $11.4 \%(n=5 / 44)$ and Kentucky $9.1 \%(n=4 / 11)$, respectively.

The univariate analysis of the concentrations of $E$. coli for variables associated with the concentrations of total coliforms, fecal coliforms, and V. parahaemolyticus, the presence of Salmonella and Shigella in the sample, and the levels of $\mathrm{Mn}, \mathrm{Pb}$ and $\mathrm{Cd}$ are presented in Table 2. The concentrations of total coliforms and fecal coliforms, and the presence of Shigella were significant parameters in Models A, B, C and D $(p<0.05)$. The presence of Salmonella in the pooled oyster samples was associated with the concentrations of E. coli (Model A and B), whereas no Salmonella was detected from estuarine waters (Model C and D). The concentrations of V. parahaemolyticus were an insignificant parameter in all statistical models. For quantitative analysis of heavy metals, the levels of Mn were a significant predictor of the concentrations of E. coli in pooled oyster meat in model A (MPN/g) and Model B $(\log M P N / g)$. On the other hand, the concentrations of $\mathrm{Cd}$ and $\mathrm{Pb}$ were associated with the concentration of E. coli of estuarine water in Model C (MPN/100 mL) and Model D $(\log M P N / 100 \mathrm{~mL})$.

In Tables 1 and 2, the significant variables with $p$-value $<0.05$ from the univariate analyses of Models A, B, C, and D were included to perform multivariate analyses to predict the concentrations of $E$. coli in oyster meat and estuarine water. The dispersion of data can be calculated based on a log likelihood function test. The mixed-effects regression models of the concentrations of $E$. coli were transformed into $\log \mathrm{MPN} / \mathrm{g}$ of pooled oyster meat in Model $\mathrm{B}$, and $\log \mathrm{MPN} / 100 \mathrm{~mL}$ of estuarine water in Model D. In the equation of a regression line, $\log M P N(y)$ was equal to $a+b x$, where $y$ is outcome or dependent variable, $\mathrm{a}$ is the $\mathrm{y}$-intercept, $\mathrm{b}$ is the slope, and $\mathrm{x}$ is predictor or independent variable. The concentrations of $E$. coli $(\mathrm{MPN})=\mathrm{e}^{(\mathrm{a}+\mathrm{bx})}$ were shown in regression equations of pooled oyster meat (Model A) and estuarine water (Model C) under the mixed-effects negative binomial regression models. 
The mixed-effects regression models between no log- and log-transformed data of concentrations of E. coli were compared in pooled oyster samples (Models A and B) and estuarine water samples (Models C and D), which are presented in Tables 3 and 4, respectively. Prior 7-day average precipitation, average ambient air temperature, and the presence of Salmonella in the pooled oyster meat were significant variables included in Model A (no log-transformed data) and Model B (log-transformed data) to predict the concentrations of E. coli in pooled oyster meat samples under mixed-effects regression models (Table 3).

Table 2. Univariate analysis of the concentrations of $E$. coli for factors associated with bacterial and chemical contamination of pooled oysters and estuarine waters.

\begin{tabular}{|c|c|c|c|c|}
\hline \multirow{2}{*}{ Parameter } & \multicolumn{2}{|c|}{ Pooled Oyster ( $p$-Value ${ }^{1}$ ) } & \multicolumn{2}{|c|}{ Estuarine Water ( $p$-Value ${ }^{1}$ ) } \\
\hline & Model A ${ }^{2}$ & Model B ${ }^{3}$ & Model C ${ }^{2}$ & Model D ${ }^{3}$ \\
\hline \multicolumn{5}{|c|}{ Concentrations of bacteria 4} \\
\hline TC concentration & $<0.0001$ & $<0.0001$ & $<0.0001$ & $<0.0001$ \\
\hline FC concentration & $<0.0001$ & $<0.0001$ & $<0.0001$ & $<0.0001$ \\
\hline VP concentration & 0.224 & 0.116 & 0.012 & 0.650 \\
\hline \multicolumn{5}{|c|}{ The present of Salmonella } \\
\hline No (reference) & - & - & - & - \\
\hline Yes & $<0.0001$ & $<0.0001$ & * & * \\
\hline \multicolumn{5}{|l|}{ The present of Shigella } \\
\hline No (reference) & - & - & - & - \\
\hline Yes & $<0.0001$ & 0.006 & $<0.0001$ & $<0.0001$ \\
\hline \multicolumn{5}{|l|}{ Heavy metal (ppm) } \\
\hline $\mathrm{Mn}$ & 0.020 & 0.002 & 0.729 & 0.343 \\
\hline $\mathrm{Cd}$ & 0.393 & 0.718 & $<0.0001$ & $<0.0001$ \\
\hline $\mathrm{Pb}$ & $<0.0001$ & 0.382 & $<0.0001$ & $<0.0001$ \\
\hline
\end{tabular}

$1 p$-values were adjusted for potential intra-group correlation within sampling locations; ${ }^{2}$ No-log data of E. coli; ${ }^{3}$ LogMPN of E. coli; ${ }^{4}$ Units of bacterial concentration is MPN/g of oyster (Model A), $\operatorname{logMPN} / g$ of oyster (Model B), MPN/100 mL of water (Model C) and $\log$ MPN/100 mL of water (Model D); * No positive Salmonella observed in estuarine water samples; TC: Total coliforms; and FC: Fecal coliforms.

Table 3. Mixed-effects regression models between no log- and log-transformed data of the concentrations of E. coli collected from pooled oyster from March 2016 and February 2017.

\begin{tabular}{cccc}
\hline Factor & Coefficient & $\mathbf{9 5 \%} \mathbf{C I}^{\mathbf{1}}$ & $p$-Value $\mathbf{~}^{\mathbf{1}}$ \\
\hline Model A: No log-transformation & & & \\
Intercept & 16.11 & 7.38 to 24.83 & $<0.0001$ \\
$\begin{array}{c}\text { Precipitation prior } 7 \text { days }(\mathrm{mm}) \\
\text { Temperature }\left({ }^{\circ} \mathrm{C}\right)\end{array}$ & $2.29 \times 10^{-2}$ & $1.36 \times 10^{-3}$ to $3.22 \times 10^{-4}$ & $<0.0001$ \\
Salmonella present in sample & -0.28 & -0.54 to -0.02 & 0.036 \\
No & & & - \\
Yes & 0.0 & - & 0.046 \\
Model B: Log-transformation & 0.62 & 0.01 to 1.23 & $<0.0001$ \\
Intercept & 7.36 & 5.04 to 9.67 & $<0.0001$ \\
Precipitation prior 7 days (mm) & $1.56 \times 10^{-2}$ & $8.72 \times 10^{-3}$ to $2.26 \times 10^{-2}$ & $<0.0001$ \\
Temperature $\left({ }^{\circ} \mathrm{C}\right)$ & -0.16 & -0.23 to -0.09 & - \\
Salmonella present in sample & & & - \\
No & 0.0 & 0.07 to 0.78 & 0.019 \\
Yes & 0.42 & &
\end{tabular}

\footnotetext{
${ }^{1}$ The $95 \%$ confidence interval (CI) and $p$-values were adjusted for potential intra-group correlation within oyster
} sampling locations.

Similar results were observed in the mixed-effects regression models of estuarine water. Seven-day average precipitation and ambient air temperature were included in the final models $(p<0.05)$ of Model C (no log-transformed data) and Model D (log-transformed data) to predict the concentrations of E. coli in $100 \mathrm{~mL}$ of estuarine water (Table 4). No positive Salmonella was detected in estuarine water 
samples, so this variable was dropped from Models $C$ and D. Other variables were also excluded from the final models due to non-significant variables $(p>0.05)$.

In the final regression models, a log scale of the original dataset, which was log of mean (Model A: MPN/g of oyster meat and Model C: MPN/100 mL of estuarine water) was compared with mean of $\log$ (Model B: $\log$ MPN/g of oyster meat and Model D: $\log$ MPN/100 mL of estuarine water) as a function of average ambient air temperature and 7-day precipitation of pooled oyster meat (Figure 1) and estuarine water (Figure 2).

Table 4. Mixed-effects regression models between log- and log-transformed data of the concentration of E. coli collected from estuarine water samples from March 2016 to February 2017.

\begin{tabular}{|c|c|c|c|}
\hline Factor & Coefficient & $95 \% \mathrm{CI}^{1}$ & $p$-Value ${ }^{1}$ \\
\hline \multicolumn{4}{|l|}{ Model C: No-log transformation } \\
\hline Intercept & 6.40 & 3.30 to 9.49 & $<0.0001$ \\
\hline Concentration of FC (MPN/100 mL) & $8.75 \times 10^{-4}$ & $5.88 \times 10^{-4}$ to $1.16 \times 10^{-3}$ & $<0.0001$ \\
\hline Precipitation prior 7 days (mm) & $2.81 \times 10^{-2}$ & $2.28 \times 10^{-2}$ to $3.33 \times 10^{-2}$ & 0.030 \\
\hline Temperature $\left({ }^{\circ} \mathrm{C}\right)$ & -0.11 & -0.20 to -0.01 & $<0.0001$ \\
\hline \multicolumn{4}{|l|}{ Model D: Log transformation } \\
\hline Intercept & 2.95 & 0.89 to 5.01 & 0.005 \\
\hline Concentration of FC (logMPN/100 mL) & $2.43 \times 10^{-4}$ & $1.47 \times 10^{-4}$ to $3.40 \times 10^{-4}$ & $<0.0001$ \\
\hline Precipitation prior 7 days $(\mathrm{mm})$ & $1.99 \times 10^{-2}$ & $1.45 \times 10^{-2}$ to $2.53 \times 10^{-2}$ & $<0.0001$ \\
\hline Temperature $\left({ }^{\circ} \mathrm{C}\right)$ & -0.07 & -0.13 to $-2.63 \times 10^{-2}$ & 0.041 \\
\hline
\end{tabular}

${ }^{1}$ The $95 \%$ confidence interval (CI) and $p$-values were adjusted for potential intra-group correlation within sampling locations; and FC, Fecal coliform.

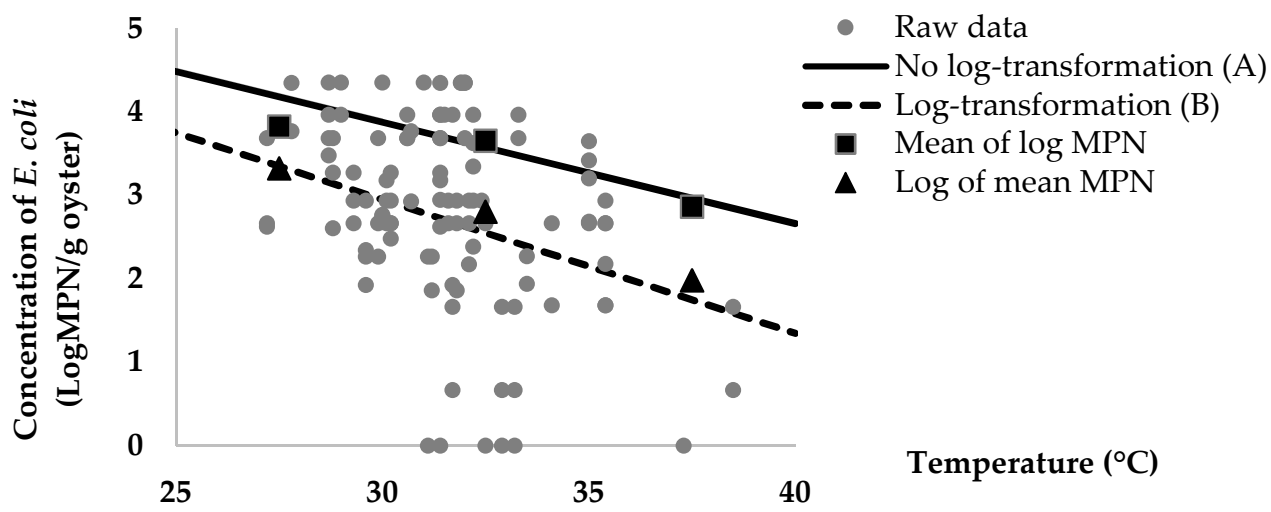

(a)

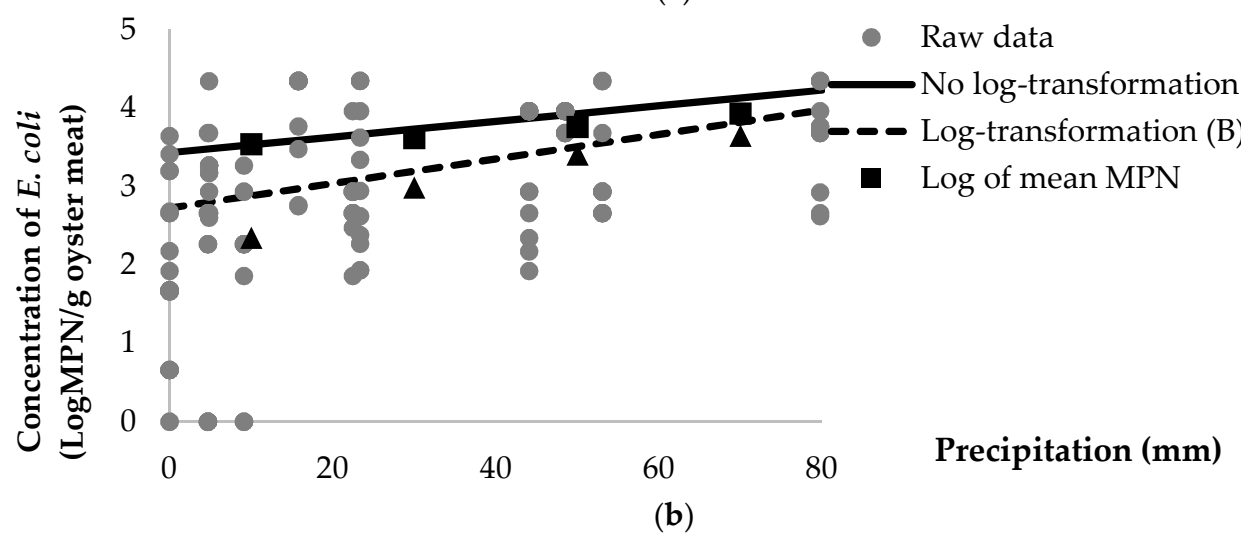

Figure 1. Predicted average population of E. coli/g of pooled oyster meat as a function of (a) ambient air temperature and (b) 7-day average precipitation between no log-transformed (Model A) and log-transformed (Model B) data. 


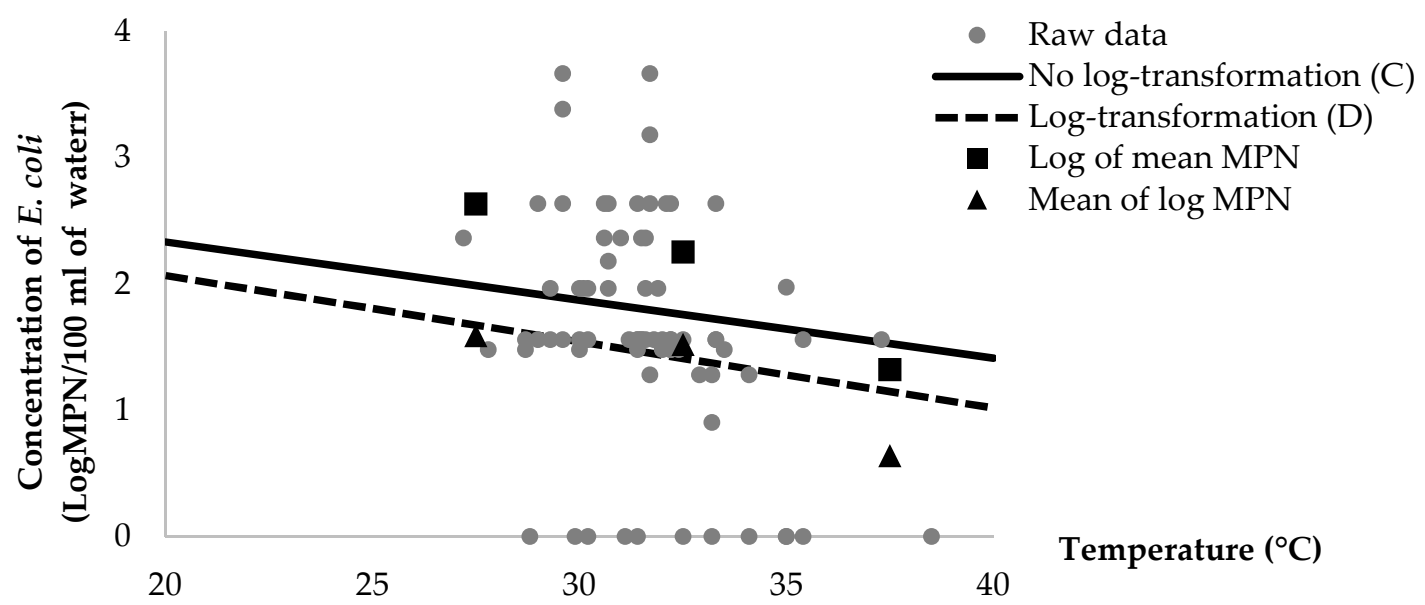

(a)

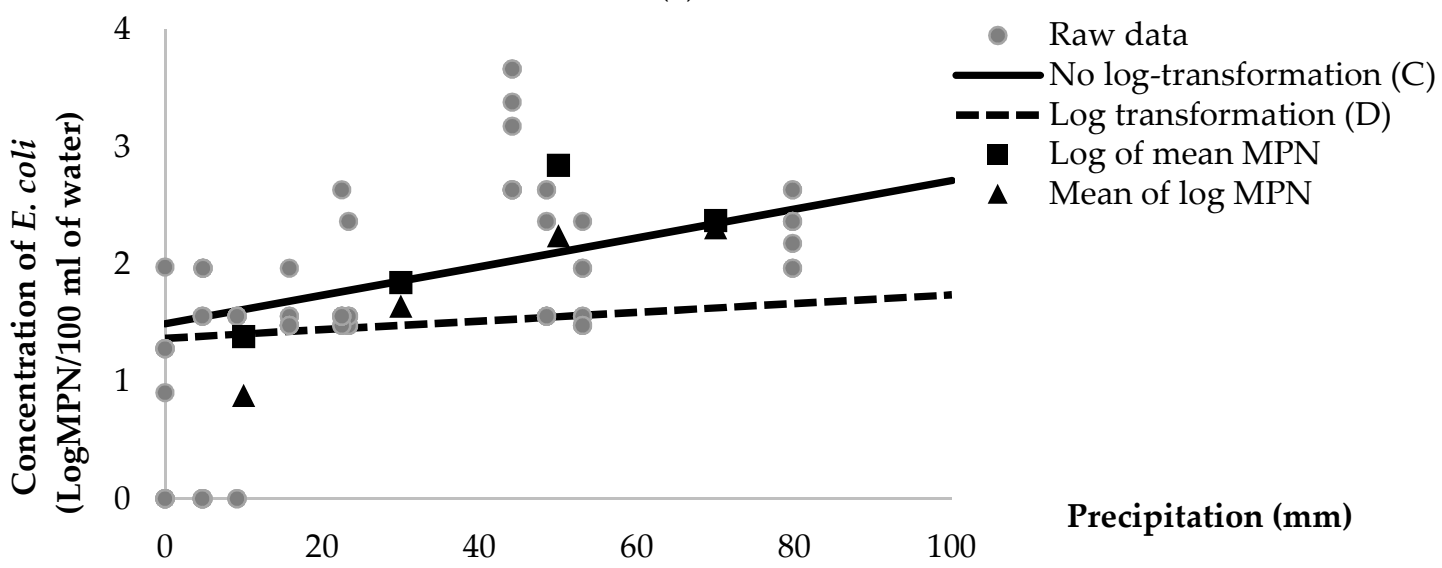

(b)

Figure 2. Predicted average population of E. coli/g of estuarine water as a function of (a) ambient air temperature and (b) 7-day average precipitation between no log-transformed (Model C) and log-transformed (Model D).

In summary, average concentrations of E. coli in oyster and estuarine water samples were compared in different ranges of temperature $\left(25-40^{\circ} \mathrm{C}\right)$ and volume of precipitation $(0-100 \mathrm{~mm})$ (Table 5). The analysis of average concentrations of E. coli from no-log transformation data shows higher concentrations than the log-transformed data. For example, in oyster samples, the different concentrations of $E$. coli in a log scale range from 0.50 to 0.88 in ambient air temperature, and from 0.28 to 1.19 in levels of precipitation. In addition, the log concentrations of $E$. coli in estuarine water samples is observed to range from 0.73 to 1.04 in ambient air temperature, and from 0.06 to 0.88 in levels of precipitation. Hence, the log of mean (Models A and B) predicts higher concentrations of E. coli than the mean of $\log$ (Models B and D). The log of mean provided proper estimation of the concentrations of $E$. coli due to the lower residue observed in the log of mean than the mean of log. 
Table 5. Summary of average concentrations of E. coli/g of oyster meat and E. coli/100 $\mathrm{mL}$ of estuarine water samples in different ranges of temperature $\left({ }^{\circ} \mathrm{C}\right)$ and 7-day precipitation averages $(\mathrm{mm})$ from March 2016 to February 2017.

\begin{tabular}{|c|c|c|c|c|c|}
\hline Sample & Parameter & $\begin{array}{l}\text { Number of } \\
\text { Sample }(\%)\end{array}$ & $\begin{array}{c}\text { Mean of Log } \\
(\mathrm{MPN} / \mathrm{g} \text { or } \\
\text { MPN/100 mL) }\end{array}$ & $\begin{array}{l}\text { Log of Mean } \\
(\mathrm{MPN} / \mathrm{g} \text { or } \\
\text { MPN/100 mL) }\end{array}$ & $\begin{array}{c}\text { Log } \\
\text { Difference }\end{array}$ \\
\hline \multirow{5}{*}{ Pooled oyster } & Temperature & & & & \\
\hline & $25.0-29.9$ & $36(25.0 \%)$ & 3.82 & 3.32 & 0.50 \\
\hline & $30.0-34.9$ & $90(62.5 \%)$ & 3.65 & 2.80 & 0.85 \\
\hline & $35.0-39.9$ & $18(12.5 \%)$ & 2.86 & 1.98 & 0.88 \\
\hline & Total & $144(100 \%)$ & 3.66 & 2.83 & 0.83 \\
\hline \multirow{5}{*}{ Estuarine water } & Temperature & & & & \\
\hline & 25.0-29.9 & $20(20.8 \%)$ & 2.63 & 1.59 & 1.04 \\
\hline & $30.0-34.9$ & $68(70.8 \%)$ & 2.25 & 1.52 & 0.73 \\
\hline & $35.0-39.9$ & $8(8.30 \%)$ & 1.32 & 0.64 & 0.68 \\
\hline & Total & $96(100 \%)$ & 2.34 & 1.46 & 0.88 \\
\hline \multirow{6}{*}{ Pooled oyster } & Precipitation & & & & \\
\hline & 0-19.9 & $72(50.0 \%)$ & 3.54 & 2.35 & 1.19 \\
\hline & $20.0-39.9$ & $24(16.7 \%)$ & 3.62 & 2.99 & 0.63 \\
\hline & $40.0-59.9$ & $36(25.0 \%)$ & 3.76 & 3.41 & 0.35 \\
\hline & $60.0-79.9$ & $12(8.3 \%)$ & 3.93 & 3.65 & 0.28 \\
\hline & Total & $144(100 \%)$ & 3.66 & 2.83 & 0.83 \\
\hline \multirow{6}{*}{ Estuarine water } & Precipitation & & & & \\
\hline & 0-19.9 & $48(50.0 \%)$ & 1.38 & 0.88 & 0.50 \\
\hline & $20.0-39.9$ & $16(16.7 \%)$ & 1.84 & 1.64 & 0.20 \\
\hline & $40.0-59.9$ & $24(25.0 \%)$ & 2.84 & 2.24 & 0.60 \\
\hline & $60.0-79.9$ & $8(8.3 \%)$ & 2.37 & 2.31 & 0.06 \\
\hline & Total & $96(100 \%)$ & 2.34 & 1.46 & 0.88 \\
\hline
\end{tabular}

${ }^{1}$ The $\log$ difference between mean of $\log (\log \mathrm{MPN} / \mathrm{g}$ of oyster meat and $\log \mathrm{MPN} / 100$ of estuarine water) and $\log$ of mean concentration (MPN/g of oyster meat and MPN/100 mL of estuarine water) of $E$. coli.

\section{Discussion}

The ability to predict concentrations of E. coli in pooled oyster meat and estuarine water samples by using average daily and 7-days of environmental parameters, microbiological contamination and the levels of heavy metals was investigated in this study. These variables were summarized, and then univariate analyses were performed, as summarized in Tables 1 and 2. Seven-day average precipitation and ambient air temperature were significant parameters $(p<0.05)$ in the final regression models used to predict the concentrations of $E$. coli in oysters and estuarine waters. In mixed-effect regression models, the significant parameters from no log- and log-transformed data of the concentrations of $E$. coli are displayed in Models A, B, C, and D (Tables 3 and 4). Other non-significant variables $(p>0.05)$ such as maximum wind gust, current wind speed, the concentrations of $V$. parahaemolyticus, and the levels of heavy metal were dropped from the final regression models. The lack of significance among these variables is possibly due to lack of variability of the data presented during sample collection. For example, one-day current wind values ranged between 0 and $1.5(\mathrm{SD} \pm 0.4) \mathrm{m} / \mathrm{s}$, which was typically constant over the 12-month period of the study. Additionally, average 7-day current wind speed had a mean of $1.0 \mathrm{~m} / \mathrm{s}$ with SD $0.4 \mathrm{~m} / \mathrm{s}$, values which were also consistent over time. This finding was similar to the consistency of the concentrations of $\mathrm{Mn}, \mathrm{Pb}$ and $\mathrm{Cd}$ observed in all samples from oyster meat and estuarine water. Hence, these consistent variables were dropped from the final regression model due to their homogeneity. Thus, fluctuating environmental parameters are the only ones found to be of significance in predicting concentrations of E. coli contamination in oysters and estuarine waters.

In our final regression models, 7-day averages for precipitation and daily ambient air temperature were significant predictors for estimating the concentrations of $E$. coli in pooled oyster meat observed in Models A and B, and estuarine water samples observed in Models C and D. The levels of precipitation 
were also positively associated with the concentrations of E. coli, while a negative relationship was observed between ambient air temperature and the concentrations of $E$. coli in pooled oyster meat and estuarine water samples. These findings are supported by the study from Scopel et al. which found that, on average, the accumulation of E. coli in seawater increased up to $2 \log$ colony forming unit (CFU) with the observed highest concentration at $4500 \mathrm{CFU} / 100 \mathrm{~mL}$ after precipitation at a beach [25]. A positive correlation between the impact of precipitation and concentrations of $E$. coli was also observed among blue mussels [26]. This study suggests that precipitation can introduce microbial contaminants to coastal areas and other locations of oyster cultivation. One possible explanation would be run off water from nearby communities and discharges from municipal water may wash fecal contamination into oyster cultivating areas. During periods of higher precipitation, there is a greater likelihood of detecting E. coli in both oyster meat and estuarine water. This finding is supported by many studies, which is reinforced by the fact that waterborne disease outbreaks have been increasingly reported during periods of rainfall, where heavy rain-washed microbial contaminants into areas of oyster cultivation $[27,28]$.

Considering the temperature parameters, a negative relationship was observed in this study between ambient air temperature and the concentrations of E. coli. Other published papers support the suggestion that the rate of inactivation of E. coli is positively associated with temperature [29]; in addition, tendency towards high bacterial accumulation in clams was observed when the temperature increased [30]. The optimal temperature of maximal clearance of Ostrea edulis oysters falls in a temperature range between $12{ }^{\circ} \mathrm{C}$ and $19^{\circ} \mathrm{C}$ (Šolić et al., 1999). This study found that temperature and precipitation are key factors that influence the survival of $E$. coli in oyster meat and estuarine water.

Models of log-transformed data have been regularly used for predicting of bacterial inactivation and persistence in the environment, as well as food commodities [31,32]. In this study, the concentrations of E. coli were normalized by using log transformation, and then regressed by significant variables, as presented in Model B of pooled oyster meat $(\log \mathrm{MPN} / \mathrm{g}$ of oyster) and Model D of estuarine water ( $\log$ MPM/100 mL of estuarine water). The value of log concentrations of $E$. coli in models B and D was lower than no-log transformation of $E$. coli in models A and C when the log-transformed data was calculated back to raw or original data (Figures 1 and 2). Our study elaborated that log transformed data of bacterial concentration underestimates predicted values of E. coli contamination of oyster meat and estuarine water samples. This finding on the normalized data could introduce a bias for bacterial estimation according to Jensen's inequality theorem [33]. Jensen's equality is explained by an equation in which the log of mean is greater than or equal to mean of log. Moreover, our results showed that the no-log transformation data provides more accurate estimation on the concentrations of E. coli in both pooled oyster meat and estuarine water samples.

Subsequently, mixed-effects negative binomial regression models were performed to predict the concentrations of E. coli in Model A of oyster and Model C of estuarine water. The negative binomial regression model is suitable for overly dispersed count data, and this method has been widely used in microbiological studies, such as pre-harvest contamination of indicator and pathogenic bacteria in mixed produce, and the impact of farm management and environmental factors on the level of indicator bacteria in spinach [34-36]. Furthermore, more advanced studies on diversity of microbial ecological interaction networks on metagenomic data and microbiome count data have also used negative binomial regression to generate proper statistical models [37-39]. However, many microbiological studies use log transformation to exhibit the distribution of bacteria in various food commodities due to the fact that it is easy to perform when diversity of bacteria is observed.

The log-transformed data provided lower estimates of concentrations of $E$. coli after being transformed to raw data, compared to no log-transformation. For example, with average ambient air temperature of $28^{\circ} \mathrm{C}$ and 7-day average levels of precipitation at $19.11 \mathrm{~mm}$, the mean of log was 3.59 (Model B) and the observed log of mean was 4.05 (Model A). The log difference between a log of mean and a mean of $\log$ concentration of E. coli was $0.46 \log (4.05-3.59=0.46)$, which is presented in Figure 1. More specifically, each additional degree Celsius of ambient air temperature is associated 
with a $31 \%\left(10^{-0.16}=0.69\right)$ decrease in the concentration of E. coli when transformed to raw data in model B. A higher rate of reduction in the concentration of E. coli is observed in model B, as compared with model A. For example, each additional degree Celsius of air temperature in model A is related to a $24 \%\left(\mathrm{e}^{-0.28}=0.76\right)$ reduction in the concentration of E. coli (Table 3).

A similar result was seen with the 7-day average level of precipitation, with each additional millimeter of average precipitation in Model B associated with a $4 \%\left(10^{-0.0156}=0.96\right)$ decrease in the concentration of E. coli. Each additional millimeter of 7-day average precipitation in Model A, by contrast, is associated with a $2 \%\left(\mathrm{e}^{-0.0229}=0.98\right)$ reduction in E. coli in pooled oyster meat (Table 3). Even though the difference between the concentrations of E. coli in Models A and B was not great, both models differ substantially in their predictions, as shown in Figure 1. Interestingly, despite the fact that these bacteria are considered to be pathogens, few bacterial cells lead to serious complications with regard to human health.

In Models $\mathrm{C}$ and $\mathrm{D}$, the concentrations of fecal coliforms, average ambient air temperature and 7-day precipitation were significant parameters for predicting the concentrations of $E$. coli in estuarine water samples. In Model D, each additional degree (Celsius) of ambient air temperature is associated with a $15 \%\left(10^{-0.07}=0.85\right)$ reduction in the concentration of $E$. coli when transformed to raw, or original, data. In Model C, a $10 \%\left(\mathrm{e}^{-0.11}=0.90\right)$ decrease in the concentration of E. coli is associated with this same increase in temperature (Table 4). Similarly, focusing on the level of precipitation, each additional of millimeter of 7-day average precipitation is associated with a $4 \%\left(10^{-0.0199}=0.96\right)$ decrease in the concentrations of E. coli in Model D, whereas a 3\% $\left(\mathrm{e}^{-0.0281}=0.97\right)$ reduction in the concentrations of E. coli is observed in the Model C (Table 4). Fecal coliforms are a significant variable for estimating the concentration of $E$. coli in estuarine water, although the rate of reduction in the concentration of E. coli was similar in Model C $\left(\mathrm{e}^{0.000875}=1.0\right)$ and Model D $\left(10^{-0.000243}=1.0\right)$. Even though these significant variables are not greatly different between models $C$ and $D$, the intercept coefficients showed largely dissimilar values, as displayed in Table 4 . Using the averages of all significant variables, the $\log$ concentrations of E. coli were at approximately 1.74 and $1.47 \log \mathrm{MPN} / 100 \mathrm{~mL}$ of estuarine water in Models $C$ and D, respectively. This result indicates that log-transformed data provides a lower prediction of $E$. coli populations compared with no-log transformed data.

Concentrations of indicator bacteria have varying ranges, depending on geographical location, environmental parameters, and the presence of pathogenic bacteria. For example, the concentrations of total and fecal coliforms in oyster meat harvested in Korea were detected from 65.6 to $127.1 \mathrm{MPN} / 100 \mathrm{~g}$ of total coliforms and 23.7 to $26.7 \mathrm{MPN} / 100 \mathrm{~g}$ of fecal coliforms, respectively [40]. The finding was supported by a study from Mok et al. that showed similar concentrations of fecal coliforms as in Korea. The concentrations of E. coli can be used to estimate the pathogenic bacterial contamination of shellfish. The low levels of E. coli load in shellfish indicates that Salmonella contamination may be absent from these shellfish [41]. The presence of indicator bacteria of bivalves suggests that the environment is polluted, and aquatic animals and their products are possibly contaminated.

The limitations of this study include the limited ranges of the observed parameters such as temperature (between $25^{\circ} \mathrm{C}$ and $40{ }^{\circ} \mathrm{C}$ ) and the level of precipitation (which did not exceed $100 \mathrm{~mm}$ ). Thus, the prediction of the concentrations of $E$. coli should be estimated and interpreted within the provided ranges observed in this study. This finding cannot generalize about outside ranges to predict the concentration of $E$. coli. This study suggests that monitoring of environmental factors associated with the concentrations of E. coli in oysters and estuarine waters should be performed regularly to decrease the risk of undetected seafood contamination. Furthermore, use of no-log transformation will provide better estimates and less bias than log transformed data.

\section{Conclusions}

Fresh oysters and estuarine water can become contaminated with non-pathogenic and pathogenic bacteria of public health significance. Environmental factors used to predict the concentrations of such bacteria should provide a useful tool for detecting non-pathogenic bacteria, and possibly identifying 
pathogenic bacterial contamination before oysters are harvested. Certain environmental parameters such as precipitation and ambient air temperature were found to be significantly associated with the concentrations of $E$. coli in oyster meat and estuarine water samples. To conclude, no-log transformed data should be utilized, rather than log-transformed data, to predict the concentrations of $E$. coli in order to achieve the most precise estimation. This piece of information can also be applied to other quantitative microbiological studies to enhance precision and reduce the bias of the studies.

Author Contributions: Conceptualization, E.R.A.; methodology, S.J. and E.R.A.; formal analysis, S.J.; data curation, S.J.; writing —original draft preparation, S.J.; writing—review and editing, S.J. and E.R.A.

Funding: This research was funded by the grant for development of New Faculty Staff Ratchadapiseksomphot Endowment Fund Grant number (RGN_2559_038_02_31), Chulalongkorn University-Veterinary Science Fund (RG17/2559), Thailand and Chulalongkorn University Office of International Affairs Scholarship for Short-term Research.

Acknowledgments: We thank Chilai Kuwatananukul at the Department of Veterinary of Public Health, Faculty of Veterinary Science, Chulalongkorn University for technical laboratory assistance.

Conflicts of Interest: The authors declare no conflict of interest.

\section{References}

1. Liang, L.; He, B.; Jiang, G.; Chen, D.; Yao, Z. Evaluation of mollusks as biomonitors to investigate heavy metal contaminations along the Chinese Bohai Sea. Sci. Total Environ. 2004, 324, 105-113. [CrossRef] [PubMed]

2. Brands, D.A.; Inman, A.E.; Gerba, C.P.; Maré, C.J.; Billington, S.J.; Saif, L.A.; Levine, J.F.; Joens, L.A. Prevalence of Salmonella spp. in Oysters in the United States. Appl. Environ. Microbiol. 2005, 71, 893-897. [CrossRef] [PubMed]

3. Hellberg, R.S.; Chu, E. Effects of climate change on the persistence and dispersal of foodborne bacterial pathogens in the outdoor environment: A review. Crit. Rev. Microbiol. 2016, 42, 548-572. [CrossRef]

4. McLaughlin, J.B.; DePaola, A.; Bopp, C.A.; Martinek, K.A.; Napolilli, N.P.; Allison, C.G.; Murray, S.L.; Thompson, E.C.; Bird, M.M.; Middaugh, J.P. Outbreak of Vibrio parahaemolyticus gastroenteritis associated with Alaskan oysters. N. Engl. J. Med. 2005, 353, 1463-1470. [CrossRef] [PubMed]

5. Raszl, S.M.; Froelich, B.A.; Vieira, C.R.; Blackwood, A.D.; Noble, R.T. Vibrio parahaemolyticus and Vibrio vulnificus in South America: Water, seafood and human infections. J. Appl. Microbiol. 2016, 121, 1201-1222. [CrossRef] [PubMed]

6. Iwamoto, M.; Ayers, T.; Mahon, B.E.; Swerdlow, D.L. Epidemiology of seafood-associated infections in the United States. Clin. Microbiol. Rev. 2010, 23, 399-411. [CrossRef] [PubMed]

7. Le, Q.; Bach, L.; Arai, T. Monitoring heavy metal contamination using rocky oyster (Saccostrea glomerate) in Haiphong-Halong coastal area, North Vietnam. Int. J. Environ. Res. 2015, 9, 1373-1378.

8. Muñoz Sevilla, N.P.; Villanueva-Fonseca, B.P.; Góngora-Gómez, A.M.; García-Ulloa, M.; Domínguez-Orozco, A.L.; Ortega-Izaguirre, R.; Campos Villegas, L.E. Heavy metal concentrations in diploid and triploid oysters (Crassostrea gigas) from three farms on the north-central coast of Sinaloa, Mexico. Environ. Monit. Assess. 2017, 189, 536. [CrossRef] [PubMed]

9. Silva, A.I.; Vieira, R.H.; Menezes, F.G.; Fonteles-Filho, A.A.; Torres, R.C.; Sant'Anna, E.S. Bacteria of fecal origin in mangrove oysters (Crassostrea rhizophorae) in the Cocó River estuary, Ceará State, Brazil. Braz. J. Microbiol. 2004, 35, 126-130. [CrossRef]

10. Jozić, S.; Šolić, M.; Krstulović, N. The accumulation of the indicator bacteria Escherichia coli in mussels (Mytilus galloprovincialis) and oysters (Ostrea edulis) under experimental conditions. Acta. Adriatica. 2012, 53, 353-361.

11. Forcelini, H.C.D.L.; Kolm, H.E.; Absher, T.M. Escherichia coli in the surface waters and in oysters of two cultivations of Guaratuba Bay-Paraná-Brazil. Braz. Arch. Biol. Technol. 2013, 56, 319-326. [CrossRef]

12. Haendiges, J.; Jones, J.; Myers, R.A.; Mitchell, C.S.; Butler, E.; Toro, M.; Gonzalez-Escalona, N. A nonautochthonous US strain of Vibrio parahaemolyticus isolated from Chesapeake Bay oysters caused the outbreak in Maryland in 2010. Appl. Environ. Microbiol. 2016, 82, 3208-3216. [CrossRef] [PubMed]

13. Tirado, M.; Clarke, R.; Jaykus, L.; McQuatters-Gollop, A.; Frank, J. Climate change and food safety: A review. Food Res. Int. 2010, 43, 1745-1765. [CrossRef] 
14. Garreis, M.J. Sanitary Surveys of Growing Waters. In Environmental Indicators and Shellfish Safety; Hackney, C.R., Pierson, M.D., Eds.; Chapman and Hall: New York, NY, USA, 1994; pp. 289-330.

15. Commission Regulation (EC) No. 2073/2005 on Microbiological Criteria for Foodstuffs. European Commission 2005. Available online: https://eurlex.europa.eu/eli/reg/2005/2073/oj (accessed on 1 April 2018).

16. U.S. Food and Drug Administration (FDA). National Shellfish Sanitation Program (NSSP), Guide for the Control of Molluscan Shellfish. Available online: https:/www.fda.gov/food/guidanceregulation/ federalstatefoodprograms/ucm2006754.htm (accessed on 31 January 2019).

17. Ministry for Primary Industries, New Zealand Government Animal Products Notice (Specifications for Bivalve Molluscan Shellfish for Human Consumption) 2006. Available online: https://www.mpi.govt.nz/ dmsdocument/20999/send (accessed on 31 April 2019).

18. Jeamsripong, S.; Chuanchuen, R.; Atwill, E.R. Assessment of Bacterial Accumulation and Environmental Factors in Sentinel Oysters and Estuarine Water Quality from the Phang Nga Estuary Area in Thailand. Int. J. Environ. Res. Public Health 2018, 15, 9. [CrossRef] [PubMed]

19. Feng, P.; Weagant, S.D.; Grant, M.A.; Burkhardt, W.; Shellfish, M.; Water, B. BAM: Enumeration of Escherichia coli and the Coliform Bacteria. Bacteriological Analytical Manual (BAM), 2002. Available online: http://www.fda.gov/Food/FoodScienceResearch/LaboratoryMethods/ucm064948.htm (accessed on 29 March 2019).

20. Kaysner, C.A.; DePaola, A. Bacteriological Analytical Manual (BAM): Vibrio. 2004. Available online: https://www.fda.gov/food/foodscienceresearch/laboratorymethods/ucm070830.htm (accessed on 31 March 2019).

21. Andrews, W.H.; Jacobson, A. BAM: Shigella. Available online: https://www.fda.gov/food/ foodscienceresearch/laboratorymethods/ucm070789.htm (accessed on 31 January 2018).

22. Andrews, W.H.; Wang, H.; Jacobson, A.; Hammack, T. BAM: Salmonella. 2007. Available online: https:// www.fda.gov/Food/FoodScienceResearch/LaboratoryMethods/ucm070149.htm (accessed on 1 January 2019).

23. Grimont, P.A.; Weill, F.-X. Antigenic Formulae of the Salmonella Serovars, 9th ed.; WHO Collaborating Centre for Reference and Research on Salmonella: Paris, France, 2007.

24. Association of Official Analytical Chemists (AOAC). Official Methods of Analysis; AOAC: Washington, DC, USA, 1975.

25. Scopel, C.O.; Harris, J.; McLellan, S.L. Influence of Nearshore Water Dynamics and Pollution Sources on Beach Monitoring Outcomes at Two Adjacent Lake Michigan Beaches. J. Great Lakes Res. 2006, 32, 543-552. [CrossRef]

26. Lunestad, B.T.; Frantzen, S.; Svanevik, C.S.; Roiha, I.S.; Duinker, A. Time trends in the prevalence of Escherichia coli and enterococci in bivalves harvested in Norway during 2007-2012. Food Control. 2016, 60, 289-295. [CrossRef]

27. Cann, K.F.; Thomas, D.R.; Salmon, R.L.; Wyn-Jones, A.P.; Kay, D. Extreme water-related weather events and waterborne disease. Epidemiol. Infect. 2013, 141, 671-686. [CrossRef]

28. Nichols, G.; Lane, C.; Asgari, N.; Verlander, N.Q.; Charlett, A. Rainfall and outbreaks of drinking water related disease and in England and Wales. J. Water Health 2009, 7, 1-8. [CrossRef]

29. Blaustein, R.A.; Pachepsky, Y.; Hill, R.L.; Shelton, D.R.; Whelan, G. Escherichia coli survival in waters: Temperature dependence. Water Res. 2013, 47, 569-578. [CrossRef]

30. Campos, C.J.; Cachola, R.A. Faecal coliforms in bivalve harvesting areas of the Alvor lagoon (Southern Portugal): Influence of seasonal variability and urban development. Environ. Monit. Assess. 2007, 133, 31-41. [CrossRef]

31. Atidégla, S.C.; Huat, J.; Agbossou, E.K.; Saint-Macary, H.; Glèlè Kakai, R. Vegetable Contamination by the Fecal Bacteria of Poultry Manure: Case Study of Gardening Sites in Southern Benin. Int. J. Food Sci. Nutr. 2016, 1-8. [CrossRef] [PubMed]

32. Mritunjay, S.K.; Kumar, V. A study on prevalence of microbial contamination on the surface of raw salad vegetables. Biotech 2017, 7. [CrossRef] [PubMed]

33. Hansen, F.; Pedersen, G.K. Jensen's Operator Inequality. Bull. London Math. Soc. 2003, 35, 553-564. [CrossRef]

34. Chase, J.A.; Atwill, E.R.; Partyka, M.L.; Bond, R.F.; Oryang, D. Inactivation of Escherichia coli O157:H7 on romaine lettuce when inoculated in a fecal slurry matrix. J. Food Prot. 2017, 80, 792-798. [CrossRef] [PubMed] 
35. Pan, F.; Li, X.; Carabez, J.; Ragosta, G.; Fernandez, K.L.; Wang, E.; Thiptara, A.; Antaki, E.; Atwill, E.R. Cross-sectional survey of indicator and pathogenic bacteria on vegetables sold from Asian vendors at farmers' markets in northern California. J. Food Prot. 2015, 78, 602-608. [CrossRef] [PubMed]

36. Park, S.; Navratil, S.; Gregory, A.; Bauer, A.; Srinath, I.; Szonyi, B.; Nightingale, K.; Anciso, J.; Jun, M.; Han, D.; et al. Multifactorial effects of ambient temperature, precipitation, farm management, and environmental factors determine the level of generic Escherichia coli contamination on preharvested spinach. Appl. Environ. Microbiol. 2015, 81, 2635-2650. [CrossRef] [PubMed]

37. Biswas, S.; McDonald, M.; Lundberg, D.S.; Dangl, J.L.; Jojic, V. Learning microbial interaction networks from metagenomic count data. J. Comput. Biol. 2016, 23, 526-535. [CrossRef]

38. Kurtz, Z.D.; Müller, C.L.; Miraldi, E.R.; Littman, D.R.; Blaser, M.J.; Bonneau, R.A. Sparse and compositionally robust inference of microbial ecological networks. PLoS Comput. Biol. 2015, 11, e1004226. [CrossRef]

39. Zhang, X.; Mallick, H.; Tang, Z.; Zhang, L.; Cui, X.; Benson, A.K.; Yi, N. Negative binomial mixed models for analyzing microbiome count data. BMC Bioinformat. 2017, 18, 4. [CrossRef]

40. Mok, J.S.; Lee, T.S.; Kim, P.H.; Lee, H.J.; Ha, K.S.; Shim, K.B.; Lee, K.J.; Jung, Y.J.; Kim, J.H. Bacteriological quality evaluation of seawater and oysters from the Hansan-Geojeman area in Korea, 2011-2013: Impact of inland pollution sources. Springerplus 2016, 5, 1412. [CrossRef]

41. Hood, M.A.; Ness, G.E.; Blake, N.J. Relationship among fecal coliforms, Escherichia coli, and Salmonella spp. in shellfish. Appl. Environ. Microbiol. 1983, 45, 122-126. [PubMed]

(C) 2019 by the authors. Licensee MDPI, Basel, Switzerland. This article is an open access article distributed under the terms and conditions of the Creative Commons Attribution (CC BY) license (http://creativecommons.org/licenses/by/4.0/). 